\title{
NATURAL CONVECTION HEAT TRANSFER FLOW VISUALIZATION OF PERFORATED FIN ARRAYS BY CFD SIMULATION
}

\author{
Dhanawade Hanamant $S^{1}$, K. N. Vijaykumar ${ }^{2}$, Dhanawade Kavita ${ }^{3}$ \\ ${ }^{1}$ Professor, Smt. Indira Gandhi College of Engineering, Navi Mumbai, Maharashtra, India \\ (Research Scholar JJT University), dhanashri_hd@rediffmail.com \\ ${ }^{2}$ Professor and Head of Dept. of Mechanical Engineering, D. J Sanghvi College of Engineering, Mumbai, Maharashtra, \\ India, kotturvijaykumar@gmail.com \\ ${ }^{3}$ Assistant Prof. Department of Mechanical Engineering, Lokmanya Tilak College of Engineering, Navi Mumbai, \\ Maharashtra, India, nikhil_kd@rediffmail.com
}

\begin{abstract}
The present paper reports, the validation of results of modeling and simulation in CFD by experiment on the fluid flow and heat transfer characteristics of a fin arrays with lateral circular perforation and its external dimensionally equivalent solid fin arrays equipped on horizontal flat surface a problem of natural convection. The simulation is carried out using the fluid flow (CFX) workbench of ANSYS 12.0. In this study, results shows that formation of the stagnant layer around the solid fin array which slowdowns the heat dissipation rate. Increase in the fluid flow movement around the fin results increase in the heat dissipation rate. It can be achieved by adding perforation to the fins. Natural convection is a buoyancy driven phenomenon; the state of the art of CFX was used to carry the study of fluid flow separation and velocity field over a fin array. New designed perforated fins have an improvement in average Nusselt number, over its external dimensionally equivalent solid fin arrays.
\end{abstract}

Keywords: CFD simulation, perforated fins, Natural convection, Heat sink, Nusselt number, Flow Visualization

\section{INTRODUCTION}

The enhancement of heat transfer is an important subject of thermal engineering. Removal of excessive heat from system components is essential to avoid the damaging effects of burning or overheating. Basically flow is nothing but circulation of the air around the heated fins surface which occurs due to the change in density of air after getting heated when it comes in contact with heated fin. Thus cold air gets sucked inside from the bottom and heated air goes up causing the natural convection currents. Mainly three types of the flow pattern are mentioned in the literature.

i) Single chimney flow pattern: Fig.1 a) this pattern is observed in lengthwise short arrays. It is formed by the cold air entering from the two ends of the arrays, traveling lengthwise and coalescing at the center of the arrays. This flow pattern is the most favorable from the heat transfer standpoint.

ii) Sliding Chimney Flow Pattern: Fig. 1 b) as the length of the arrays is increased keeping the height and spacing unaltered., it is observed that beyond a certain value of the length, the air entering from the ends is not sufficient to cool the entire arrays and leaves the array before reaching the central zone, and the resulting flow pattern is sliding chimney flow pattern, which is unsteady in nature.

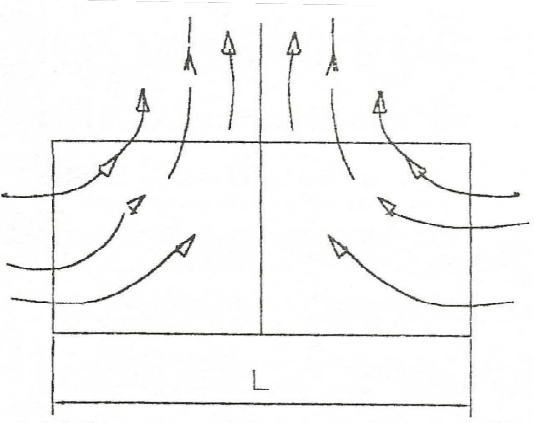

a) Single chimney flow pattern

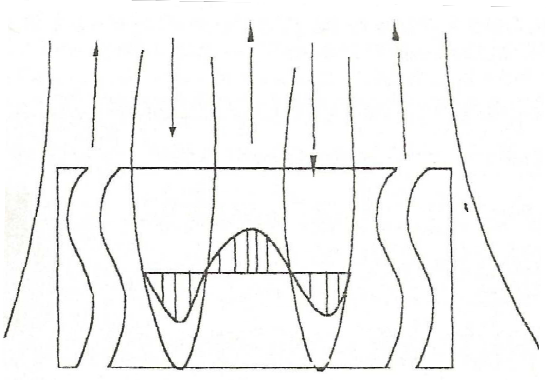

b) Sliding chimney 


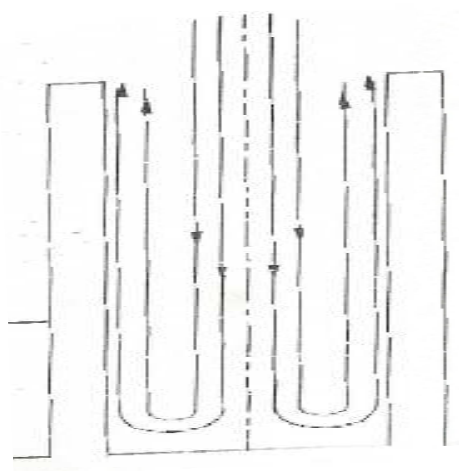

c) Down and up

Fig-1: Types of Flow Patterns

iii) Down and Up Flow Pattern: Fig1 c) if the length of the array is further increased so that the array can be considered infinite in the longitudinal direction, the resulting flow pattern has cold air entering at the central portion of the array, turning through $180^{\circ}$, developing boundary layers along the height of the fin flats and leaving the array in the upward direction.

It has been reported that the cross component of velocity (along the direction of the spacing) is negligible in single chimney flow pattern. The down and up flow pattern are mostly hypothetical situation and hence has little practical significance.

Abdullah H. AIEssa et al. [1-2] studied the heat dissipation from a horizontal rectangular fin embedded with square perforation, rectangular perforations with an aspect ratio of two, equilateral triangular perforations of bases parallel and towards its fin tip, by using the finite element technique under natural convection. They compared the results of the perforated fin with its external dimensionally equivalent solid fin. They showed that perforation in the fins enhances heat dissipation rates and at the same time decreases the expenditure for the fin material. Sanjeev D. Suryawanshi and Narayan K. Sane [3] investigated experimentally the heat dissipation from a fin array with an inverted notch at the central bottom portion of the fin to modify its geometry for the enhancement of heat transfer on normal and inverted notched fin arrays. Also they observed the single chimney flow pattern for INFAs. C. B. Sobhan [4] on free convection heat transfer from fins and fin arrays attached to a heated horizontal base by applying the differential interferometry technique. They have calculated the heat transfer coefficient, Nusselt number, considering the fin spacing and the thermal conductivity as parameters. The correlations are presented concerning the overall Nusselt number with the relevant parameters. The optimum fin spacing depends on the thermal conductivity of the material. They observed the different flow patterns by using the interfometry technique. Suneeta Sane et.al [5] has performed the studies on the rectangular notched fin arrays; they observed that total heat flux and the heat transfer coefficient increase as the notch depth increases. The area removed due to notch is compensated by the air entry at the ends of the fin it provides fresh cold air to bring in contact with hot fin surfaces. They also carried the flow visualization of the fluid flow around the fin by using the simple smoke technique using the Dhoop stick. They found that the cold air is sucked inside from the bottom of the fin and leaving from the central portion of the fin forming the single chimney pattern. Vinod M. Wankar S.G. Taji [6] in their experimental investigation of flow pattern on rectangular fin arrays under natural convection carried the flow visualization studies by simple smoke technique using the Dhoop stick on the rectangular fin arrays of varying the fin spacing they obtained for $2 \mathrm{~mm}, 4 \mathrm{~mm}$, $6 \mathrm{~mm}$ fin spacing, the scattered flow pattern. While for $12 \mathrm{~mm}$ fin spacing they observed the single chimney flow pattern which gives the higher heat transfer coefficient. The present paper reports, CFD modeling and simulation using ANSYS 12.0 in the workbench of fluid flow (CFX), of the fluid flow and heat transfer characteristics of a rectangular fin arrays equipped with circular perforation on a horizontal flat surface and its external dimensionally equivalent solid fin arrays. The studies were carried by varying the diameter $(8 \mathrm{~mm}$ and $12 \mathrm{~mm}$ ) of circular perforations and heat inputs. Geometric dimensions of the perforated fin arrays and its external dimensionally equivalent non perforated fin arrays were same and those were $\mathrm{H}=65 \mathrm{~mm}, \mathrm{~L}=100 \mathrm{~mm}, \mathrm{~S}=30 \mathrm{~mm}$. The simulation results are validated by experimentation by taking repeated steady state readings.

\section{EXPERIMENTAL SETUP}

The main requirement of the natural convection heat transfer experiment is controlled environmental conditions. The experiment must be away from fans and flow of outside air. Hence to provide natural convection conditions, the experiment were conducted in a room where the fan was off and windows were closed so that readings should not affect by the outside atmosphere and to provide similar atmospheric conditions for all experiments.

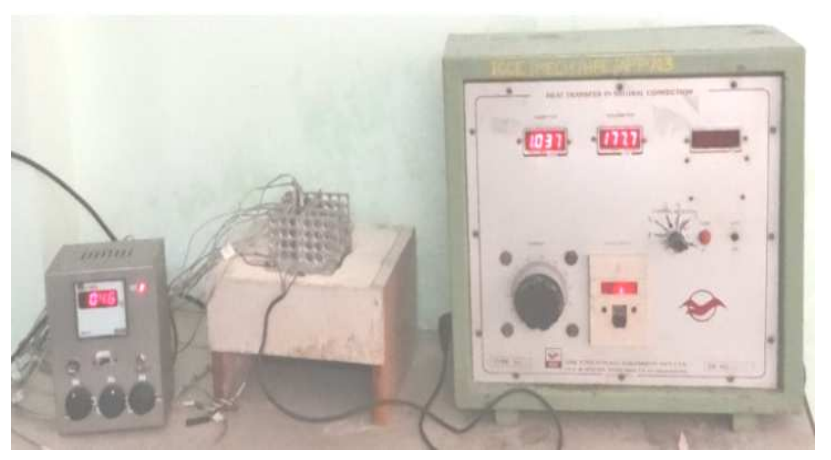

Fig-2: Photograph of the experimental setup 
Initially the supply voltage was set to $230 \mathrm{~V}$ on the stabilizer. The dimmer-stat was adjusted to get the desired input to the electric heater which multiple of voltage and current. A total of 16 Copper constantan k type thermocouple junctions (Fig.2) were fixed on different points of the fin arrays, on and beneath of the base plate and in the insulating bricks at some distance, this was done to note the temperature at various points of the fin arrays as well as to find out various heat losses to the surrounding. One thermocouple was suspended to measure the surrounding temperature. The calibrated digital temperature indicator having $0^{\circ} \mathrm{C}$ to $600^{\circ} \mathrm{C}$ range was used to measure the temperature. The heating was continued till the steady state is reached; it took 4 to 5 hours to reach steady state. Only one set of reading very carefully taken on one day, after achieving the steady state all the 16 temperature readings were noted. This procedure was repeated for all heater inputs of 40, 60, 80 and 100 Watt. Observations were repeated to confirm the validity and the readings obtained were found to be similar.

\section{DATA PROCESSING}

Net heat transfer can be calculated as

$$
\mathrm{Q}_{\mathrm{N}}=\text { ha } \mathrm{A}_{\mathrm{C}} \Delta \mathrm{T}
$$

Where,

$$
\mathrm{Q}_{\mathrm{N}}=\mathrm{Q}_{\text {Input }}-\mathrm{Q}_{\text {Cond }}
$$

To find heat loss by conduction (heat loss through the base) thermocouples were inserted through insulating bricks up to distance $\mathrm{dxb}$ from the base plate.

$$
Q_{\text {Cond }}=\frac{-k_{b} A_{\mathrm{b}} \Delta T_{\mathrm{b}}}{d x_{b}}
$$

Similarly, conduction loss through sides of base plate is also calculated by noting the temperature of side of the base plate. Average convective heat transfer coefficient,

$$
h a=\frac{Q_{N}}{A c\left(T_{s}-T_{a}\right)}
$$

Nusselt number, $N u=\frac{h_{a} H}{k}$

Rayleigh Number is given by

$$
R a=\frac{g \beta \rho^{2} C_{P}(\Delta T) H^{3}}{k \mu}
$$

Where, $\beta=\frac{1}{T_{m}}$ and $\mathrm{Tm}=(\mathrm{Ts}+\mathrm{Ta}) / 2$
Properties of air were taken from the standard table of air properties at mean Temperature $\mathrm{Tm}$.

\section{CFD MODELING AND SIMULATION}

The CFD modeling, simulation and post processing are carried out in an ANSYS 12.0, Workbench environment with an ANSYS system of fluid flow (CFX) [7]. It has the capability of solving the convective transport of energy by fluid flow along with the conjugate heat transfer ( $\mathrm{CHT}$ ) capability to solve the thermal conduction in solids.

In the any CFD simulation, the steps in performing fluid analysis are

1) Create or import a geometry

2) Create a mesh

3) Set up the analysis that will be sent to the solver

4) Control and monitor the solver to achieve a solution

5) Visualize the results in a post-processor and create a report.

These steps are briefed below.

\subsection{Create a Geometry}

Geometry was created using ANSYS Design Modeler software which is specifically designed for the creation and preparation of a geometry for simulation. A domain has to be built around the fin to study mass flow and thus the heat flow from the fin, because the area of interest is the outside of fin, which is the interface between the air and fin surface. Thus, connections are required between the solid fin surface and the fluid domain consisting of air.

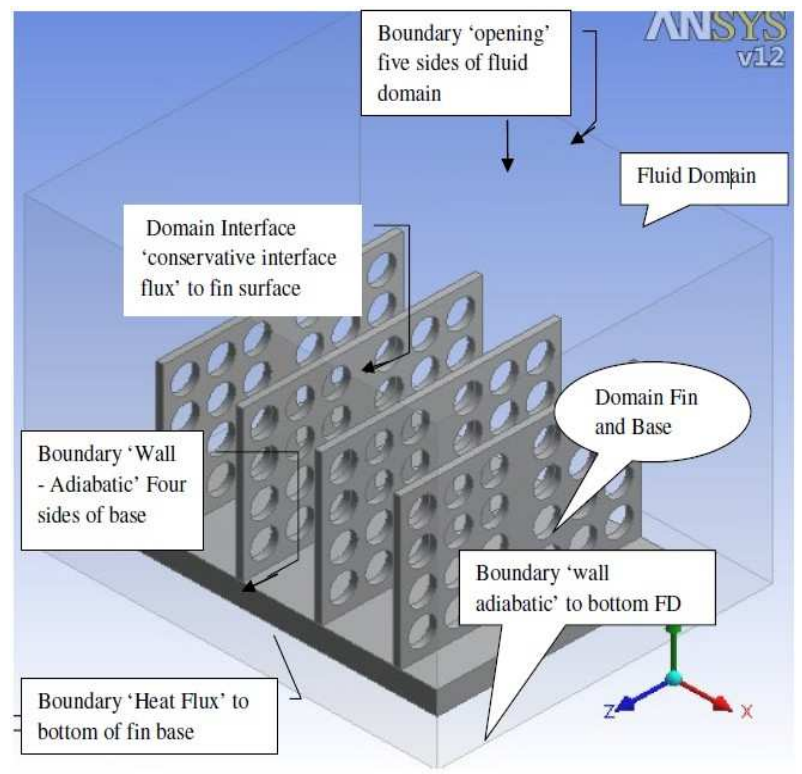

Fig-3: Domains Fluid and Solid and boundary conditions applied, the $12 \mathrm{~mm}$ perforated fin array 
Initially the domain of fin including base was created and required domain of fluid of size 172x140x130mm (Fig.3) created with the help of the 'Enclosure' option around the fin. The setup was modeled with full geometry so that maximum physics of experimental analysis can be included. Hence it is logical to assume that the behavior of the created system domains is similar to the behavior of the experimental system.

\subsection{Create a Mesh for the Geometry}

The standard volume Mesher in a CFX-Mesh is the Advancing Front Volume Mesher. It enables an automatic tetrahedral mesh generation using efficient mesh generation techniques, meshes were created with high contact sizing relevance (dense meshing near the fin surface), inflation growth rate 1.2 and total number of tetrahedral elements between 3.0 to 3.5 million.

\subsection{Setup the Analysis that will be sent to the Solver}

Under the set up of CFX of the ANSYS Workbench, selected Analysis type 'Steady State'. The appropriate boundary conditions were applied to the domains (refer Fig. 3). Materials Aluminum and Air were assigned to the created solid and fluid domain respectively. The interface between solid fin surface and fluid was created by using the option 'Domain Interface', having chosen 'Fluid Solid' interface under the basic settings. Activated buoyancy in $\mathrm{Y}$ direction, chosen Turbulence model as Laminar.

Through the use of the boundary condition of 'opening' to all sides of the enclosure faces except the bottom face (set to adiabatic) the size of the fluid domain can be reduced to a great extent and it can be assumed to be as the atmospheric conditions. Under fluid domain a layer adjacent to the bottom face of fin base was set to adiabatic. Under the domain fin and base, bottom surface of a base of the fin, set the boundary condition to 'Heat Flux'. The heat flux was applied equal to the $\mathrm{Q}_{\mathrm{N}} / \mathrm{A}_{\mathrm{b}}$ of the experimental readings. Other vertical sides of base plate set to boundary condition as adiabatic.

\subsection{Control and Monitor the Solver to Achieve a}

\section{Solution (Convergence)}

The most important measure of convergence is the residual. The CFX-Solver will terminate the run when the equation residuals (Root Mean Square (RMS) type of residual) calculated are below the residual target value. The target was set to $1.0 \times 10^{-6}$. It was observed that most solutions were getting converged between 240 to 270 iterations. In a few cases, residuals of the energy equations remain constant (about $\left.4.8 \times 10^{-6}\right)$. Hence, to optimize the computational time the maximum number of iterations was set to 300 . It took 8 to12 hours to get solutions converged.

\subsection{Visualizing the Results in a Post-Processor and} Creating a Report.

When the solver was terminated, the results were examined which is the post processing step. Temperature distribution and heat flux along the fin surface as well as parameters like Nusselt Number, heat transfer coefficient, Rayleigh number and changes in other parameters can also be predicted by computational analysis. Fig. 4 and Fig.5 shows the temperature contours over the convective surface area of the non perforated and perforated fin arrays respectively. It can be seen that the perforated fin arrays are pumping out the more heat from the base, as the average fin temperatures are higher than that of the equivalent solid fin array. The end fins and top ends of the all fins are cooled faster.

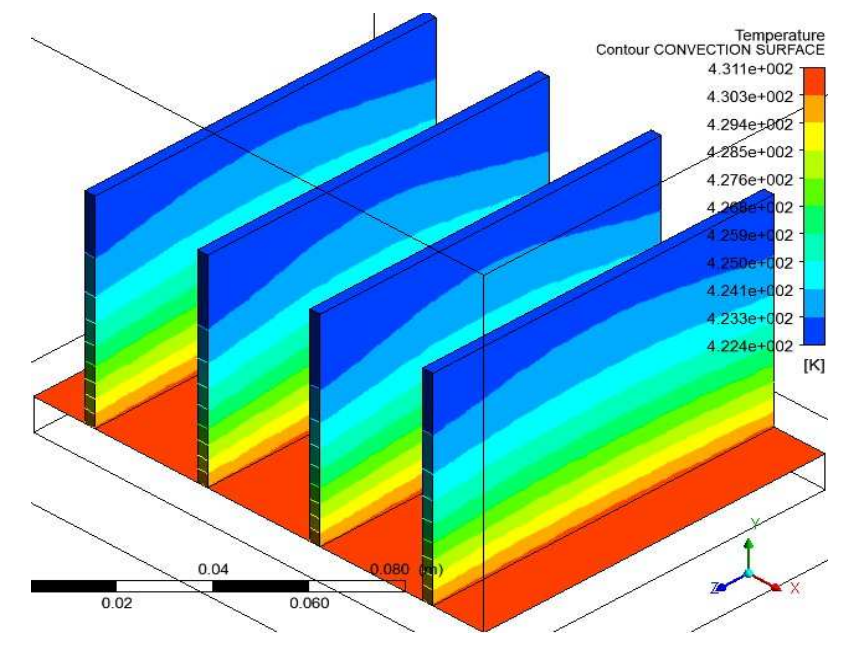

Fig-4: Contours of Temperature Solid Fin array 80W input

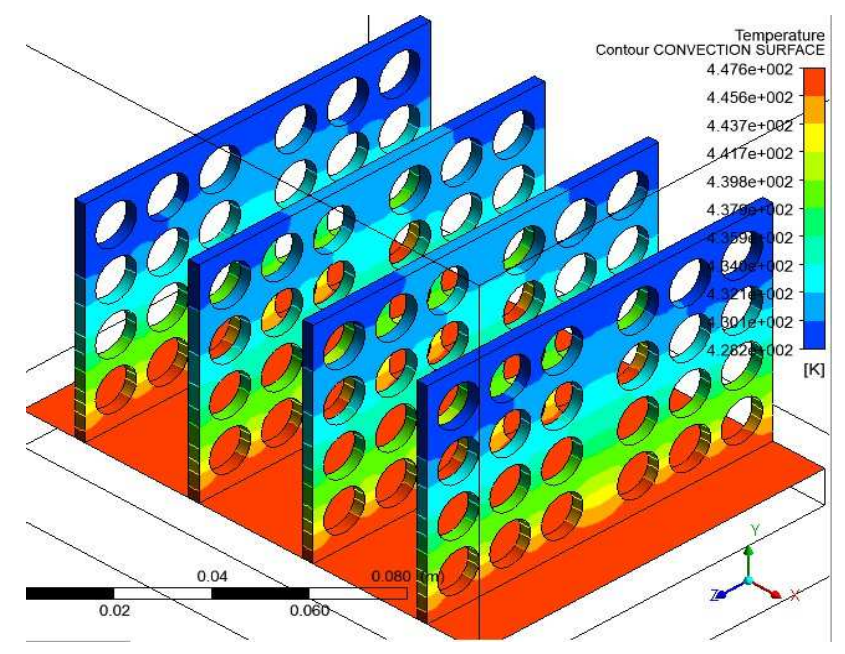

Fig-5: Contours of Temperature perforated Fin array 80W input 


\section{FLOW VISUALIZATION}

The Fig.6 shows the velocity vectors of the solid fin array at 80 watt heat input. The air has only chance to come in from the ends of the fin as seen in the interspacing of the fin. The air entering from the ends is not sufficient to cool the entire arrays and leaves the array before reaching the central zone, hence the resulting sliding chimney flow pattern. From the Fig.7 and Fig. 8 it is observed that air is sucked from the ends of the fin as well as from the sides through the perforation and goes up through the central portion of fin array.

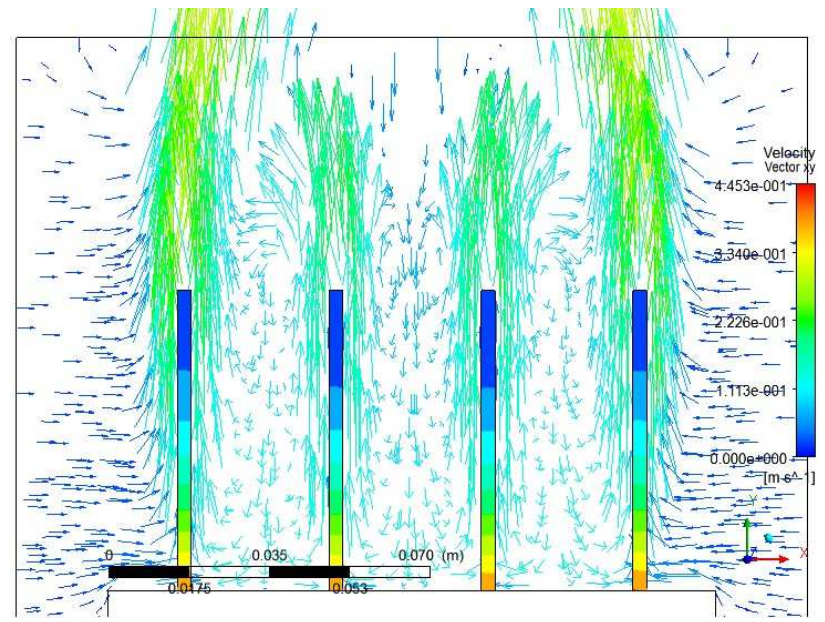

Fig-6: Vectors of velocity on $\mathrm{XY}$ plane at $\mathrm{Z}=0.02 \mathrm{~m}$ solid fin array

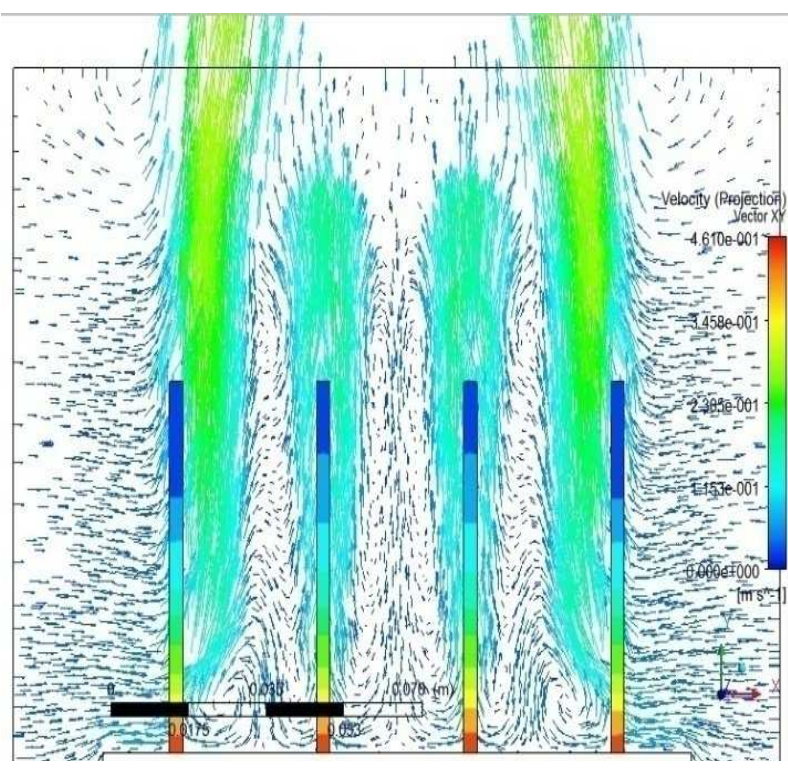

Fig-7: Vectors of velocity on $\mathrm{XY}$ plane at $\mathrm{Z}=0.02 \mathrm{~m}$ $12 \mathrm{~mm}$ perforated fin array

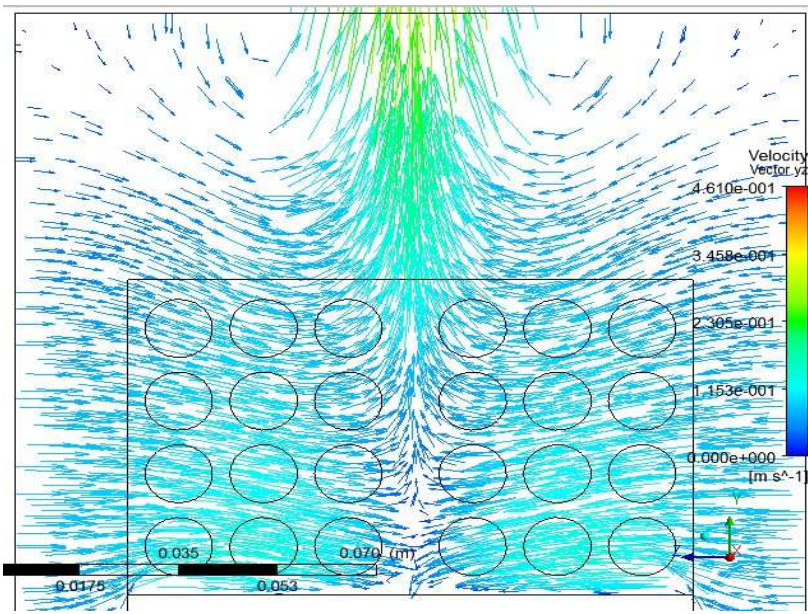

Fig-8: Vectors of velocity on $\mathrm{YZ}$ plane at $\mathrm{X}=0.06 \mathrm{~m} 12 \mathrm{~mm}$ perforated fin array

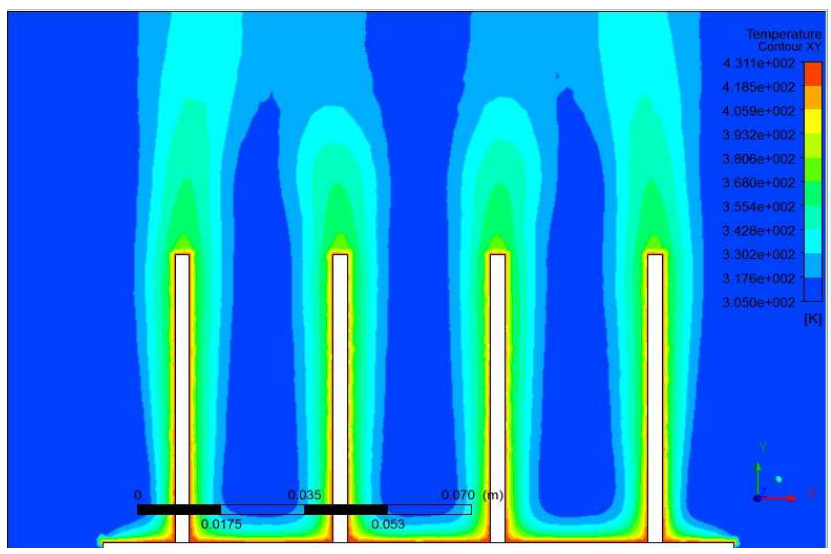

Fig-9: Contours of temperature on $\mathrm{XY}$ plane at $\mathrm{Z}=0.04 \mathrm{~m}$ solid fin array

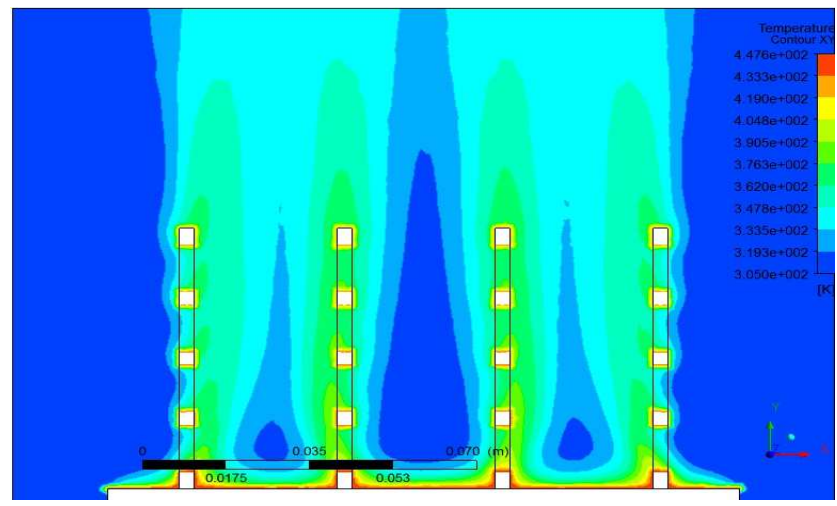

Fig-10: Contours of temperature on $\mathrm{XY}$ plane at $\mathrm{Z}=0.04 \mathrm{~m}$ $12 \mathrm{~mm}$ perforated fin array 


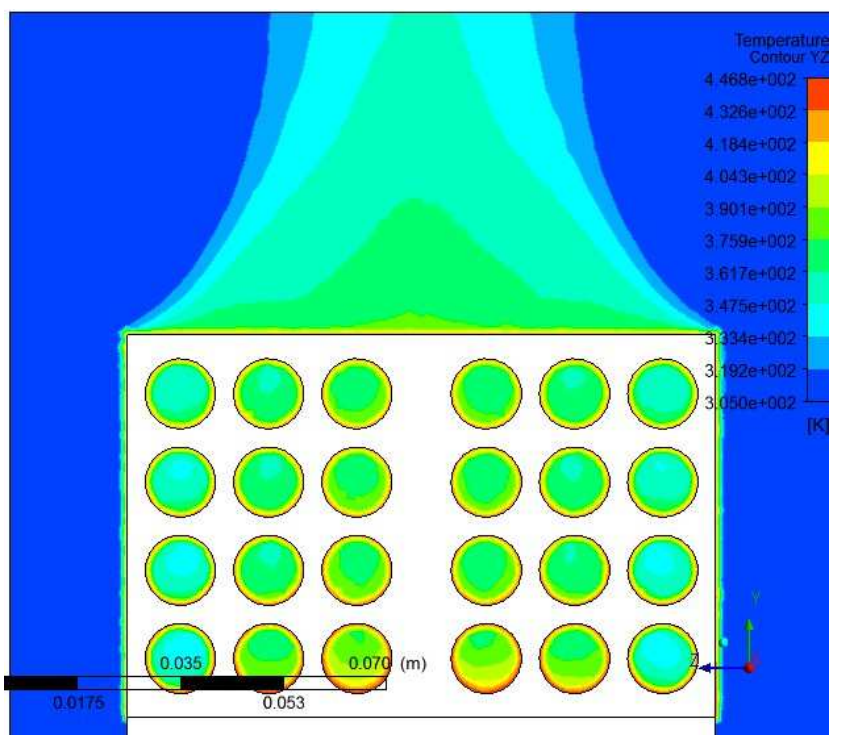

Fig-11: Contours of temperature on $Y Z$ plane at $X=0.103 \mathrm{~m}$ $12 \mathrm{~mm}$ perforated fin array

Showing the single chimney flow pattern, the space between middle fins showing the negligible down flow but it is better than solid fin arrays. Yet there is scope to improve the flow pattern by increasing the size of the perforation. Fig.9 shows the contours of the temperature around the solid fin, it clearly shows the formation of the stagnant hot layer. It is eased by adding the perforation to the fins as it is seen from Fig.10 the contours of temperature in the fluid domain of the $12 \mathrm{~mm}$ perforated fin. Similarly Fig.11 shows the contours of the temperature $12 \mathrm{~mm}$ perforated fin array clipped on the $\mathrm{YZ}$ plane at $\mathrm{X}=0.103 \mathrm{~m}$ all contour and velocity vectors are clipped to local range correspond to $80 \mathrm{~W}$ heat input. The Fig. 12 shows the streamlines of velocity in fluid domain of $12 \mathrm{~mm}$ perforated fin array. The air entering in the fluid domain from the bottom sides of the fluid domain which comes in contact with the heated fin surface then passes through perforation resulting in an upward flow of air by natural convection.

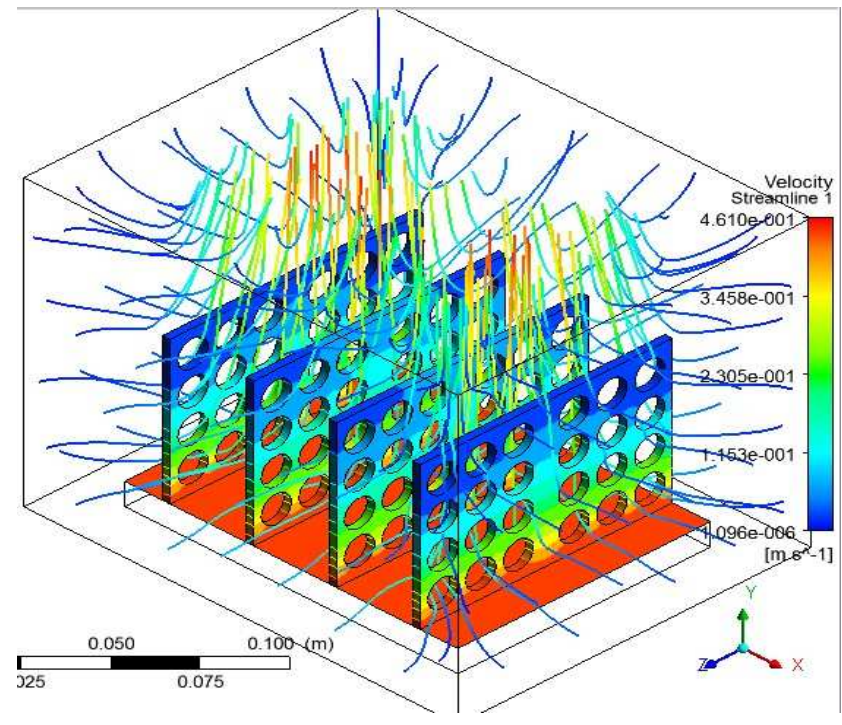

Fig-12: Streamlines of flow velocity of $12 \mathrm{~mm}$ perforated fin array at $80 \mathrm{~W}$ heat input

The attempt was made to visualize the flow pattern of the perforated fin array with simple smoke technique by using the Dhoop sticks. It was observed that the flow pattern obtained was a single chimney at the height above the fin, and slight curling of the smoke at the edge of perforation.

\section{GRID INDEPENDENCY AND VALIDATION OF}

\section{RESULTS}

A Grid independency test was carried out by varying the number of elements from 2.8 million to 3.5 million. It was observed that, a very minute variation $\left(<1^{\circ} \mathrm{c}\right)$ in various output temperatures and $<3 \mathrm{w} / \mathrm{m}^{2}$ in conserved heat flux values existed. Even though, as time was not a constraint and for accurate results the total number of tetrahedral elements in a grid were chosen to be approximately 3.0 to 3.5 million.

Comparison among the CFD simulation results and experimental values of various temperatures, heat transfer coefficient and $\mathrm{Ra}$ and $\mathrm{Nu}$ with a maximum variation of $7.5 \%$ was observed. The uncertainty analysis was carried it was found that uncertainty remains below $\pm 5 \%$, during the experimentation.

\section{RESULTS AND DISCUSSION}

Experimental analysis and CFD simulation of performance characteristics of the perforated fin arrays with $12 \mathrm{~mm}$ perforation and its external dimensionally equivalent solid fin arrays is presented.

From the presented Figs.4, 8 and 9 vectors of velocity and temperature zones around the solid fin array clears that, the air coming inwards from the bottom, gets heated as it moves 
towards the centre of the fin, rises up due to a decrease in density, the central portion of the fin becomes ineffective because the hot airstream passes over that part and therefore it does not bring about large heat transfer through that portion. When perforation is added, Figs.7, 8, 10, 11 and 12, vectors of velocity, temperature zones and streamlines of velocity around the perforated fin revels that the area removed by the perforation from the fin is compensated by the entry of more fresh cold air through the perforation and also from the ends of the fin resulting in the enhancement of the heat transfer.

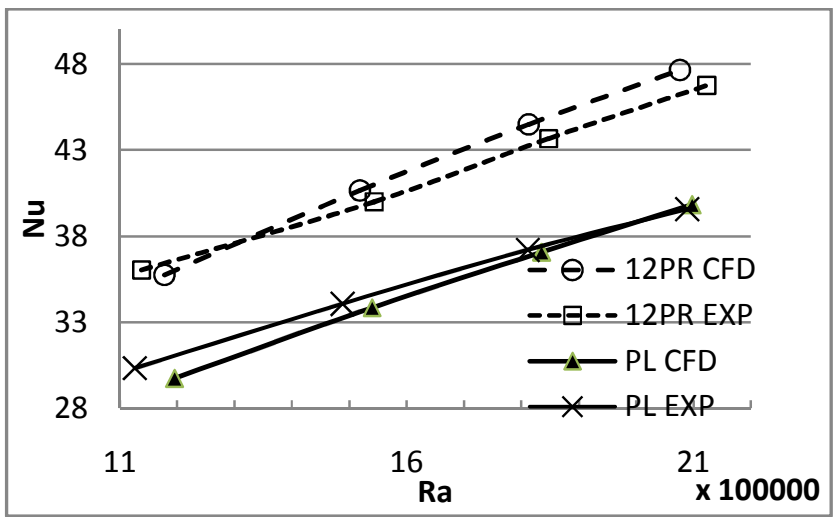

Fig- 13: Performance in $\mathrm{Nu}$ Vs Ra of $12 \mathrm{~mm}$ Perforated and corresponding external dimensionally equivalent solid fin arrays CFD and Experimental analysis

Fig.13 shows the performance of $\mathrm{Nu}$ against Rayleigh number (Ra) at the same heat input the $\mathrm{Nu}$ of the perforated fin array is higher than the $\mathrm{Nu}$ of the solid fin array of the experiment as well as of the simulation and heat dissipation rate increases with an increase in the size of the perforation.

\section{CONCLUSION}

The experimental analysis as well as the CFD simulation on a solid and a perforated fin array is carried out. The enhancement in the heat dissipation rate due to the perforation is noted and heat dissipation rate increases with an increase in the size of the perforation because of more free convection due to the perforation. The flow pattern observed in case of solid fin array was more or less in a sliding chimney in nature and that of the perforated fin array was of single chimney in nature, a significance of enhanced heat dissipation rate due to perforation.

\section{REFERENCES}

[1]. Abdullah H. AIEssa and Fayez M.S. Al-Hussien, 2004. The effect of orientation of square perforations on the heat transfer enhancement from a fin subjected to natural convection. Springer-Verlag, Heat and Mass Transfer, 40, pp. 509-515.
[2]. Abdullah H. AIEssa and Mohmmed I. Al-Widyan, 2008. Enhancement of natural convection heat transfer from a fin by triangular perforations of bases parallel and toward its tip. Applied Mathematics and Mechanics, Shanghai University and Springer-Verlag 29 (8), Pp.1033-1044.

[3]. Sanjeev D. Suryawanshi and Narayan K. Sane, 2009. Natural convection heat transfer from horizontal rectangular inverted notched fin arrays, ASME, J. Heat Transfer, 131(8).

[4]. C. B. Sobhan, S.P. Venkateshan and K. N. Seetharamu, (1990), "Experimental studies on steady free convection heat transfer from fins and fin arrays", Wärme- and Stoffübertragung, Springer-Verlag, Vol. 25, pp. 345-352.

[5]. Suneeta Sane, Gajanan Parishwad, Narayan Sane, 2009, Experimentatal Analysis of Natural Convection Heat Transfer from Horizontal Rectangular Notched Fin Arrays, International journal of Heat and Technology, Vol.27, pp11-16

[6]. Vinod M. Wankar, S.G. Taji, 2012, Experimental Investigation of Flow Pattern on Rectangular Fin Arrays under Natural Convection, International Journal of Modern Engineering Research (IJMER), Vol.2, Issue.6, pp-4572-4576.

[7]. ANSYS CFX-Solver Modeling Guide, April 2009, Release 12.0 ANSYS, Inc. Southpoint.

\section{BIOGRAPHIES}

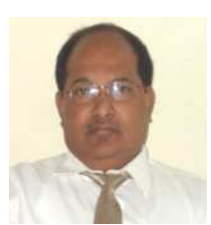

Dhanawade Hanamant S. is Professor in Smt. Indira Gandhi College of Engineering, Navi Mumbai and Research scholar of JJT University, Rajasthan, has 24 years of teaching experience and more than eleven papers in the national, international conferences and Journals in his credit. Life member of ISTE and Associate Member of IIIE

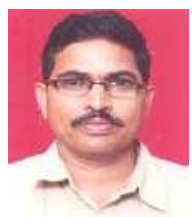

Dr. K. N. Vijaykumar is Professor and Head of the Department of Mechanical Engineering, D J. Sanghvi College of Engineering, Mumbai, has 24 years of teaching experience and more than 21 papers in the national and international conferences and Journals in his credit. Life member of ISTE and Associate Member of IIIE

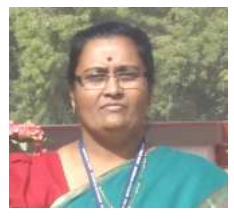

Dhanawade Kavita H. is Assistant Professor in the Department of Mechanical Engineering, Lokmanya Tilak College of Engineering, Navi Mumbai, Sixteen years of teaching experience and she has in credit more than 12 papers in the national and international conferences and journals, She is the life member of the ISTE. 


\section{NOMENCLATURE}

$\mathrm{A}_{\mathrm{b}} \quad$ Surface area of bottom of the base, $\mathrm{m}^{2}$

$\mathrm{A}_{\mathrm{c}} \quad$ Convective heat transfer area, $\mathrm{m}^{2}$

$\mathrm{C}_{\mathrm{P}} \quad$ Specific heat capacity at constant pressure, $\mathrm{Ws} / \mathrm{kgK}$

$\mathrm{dxb}$ Distance of thermocouple from base plate in the brick, $\mathrm{mm}$

g Gravity, $\mathrm{m} / \mathrm{s}^{2}$

$\mathrm{H} \quad$ Fin height, $\mathrm{mm}$

$\mathrm{h}_{\mathrm{a}} \quad$ Average heat transfer coefficient, $\mathrm{W} / \mathrm{m}^{2} \mathrm{~K}$

$\mathrm{k}$ Thermal conductivity of air, $\mathrm{W} / \mathrm{mK}$

$\mathrm{k}_{\mathrm{b}} \quad$ Thermal conductivity of insulating brick, $\mathrm{W} / \mathrm{mK}$

$\mathrm{L} \quad$ Length of fin, $\mathrm{m}$

$\mathrm{N}_{\mathrm{u}} \quad$ Nusselt number, dimensionless

$\mathrm{T}_{\mathrm{a}} \quad$ Ambient temperature, $\mathrm{K}$

$\mathrm{T}_{\mathrm{m}} \quad$ Mean temperature, $\mathrm{K}$

$\mathrm{T}_{\mathrm{s}} \quad$ Average surface temperature of a fin, $\mathrm{K}$

$\Delta \mathrm{T} \quad$ Difference of average surface temperature and ambient temperature, $\mathrm{K}$

$\Delta \mathrm{T}_{\mathrm{b}} \quad$ Difference of temperatures at bottom of the fin and temperature in a brick at $\mathrm{dx}_{\mathrm{b}}$ distance, $\mathrm{K}$

$\mathrm{Q}_{\text {Cond }} \quad$ Heat loss by conduction, W

QInput Electrical heat input, W

$\mathrm{Q}_{\mathrm{N}} \quad$ Heat transfer by Convection, $\mathrm{W}$

$\mathrm{Ra} \quad$ Rayleigh number, dimensionless

$\mathrm{S} \quad$ Fin spacing, $\mathrm{mm}$

\section{Greek Symbols}

$\beta \quad$ Coefficient of thermal expansion of air, $1 / \mathrm{K}$

$\varepsilon \quad$ Emissivity

$\rho \quad$ Density of air, $\mathrm{kg} / \mathrm{m}^{3}$

$\mu \quad$ Viscosity of air, $\mathrm{kg} / \mathrm{ms}$ 